\title{
Residual flexural strength after low-velocity impact in glass/polyester composite beams
}

\author{
C. Santiuste, S. Sanchez-Saez *, E. Barbero \\ Department of Continuum Mechanics and Structural Analysis, University Carlos III of Madrid, Avda. de la Universidad 30, 28911 Leganés, Madrid, Spain
}

\section{A R T I C L E I N F O}

Keywords:

Laminate beam

Residual flexural strength

Damage tolerance

Bending after impact test

\begin{abstract}
A B S T R A C T
This work focuses on an experimental study of flexural after impact behaviour of glass/polyester compos ite beams. The influence of impact energy, beam width, and impactor nose geometry on the residual flex ural strength was evaluated. Two widths of plain woven laminate specimens were selected. For each specimen width, the geometries of two impactor noses (Charpy and hemispherical) were chosen to carry out impact tests using a three point bending device, so that four different test configurations were exe cuted. The residual flexural strength of damaged specimens, evaluated by quasi static three point bend ing tests, was found to depend on the extent of the damage, so that the residual flexural strength was lower in the specimens in which the damage reached the edges of the beam. For this reason, the residual strength was lower in specimens impacted with a Charpy nose impactor than in the specimens impacted with a hemispherical nose impactor. Analogously, the narrower specimens presented a lower residual flexural strength than did the wider ones.
\end{abstract}

\section{Introduction}

In recent years special environmental concerns such as energy savings have developed, and the reduction of the structural weight has become a critical factor to save energy in most industries. Therefore, the use of composite materials has been extended in many engineering fields (automobile, naval, construction, etc.) due to their excellent specific properties [1]. Many structural com ponents made with composite laminates, such windmill blades, ro bot arms, transmission axes, etc., can be analysed as beams subjected to out of plane loads that cause mainly bending mo ments and also shear forces [2]. These loads can be dynamic, as these structures can, for example, be subjected to impact during assembly and maintenance operations, or during service life. Com posite laminates are especially sensitive to low velocity impacts since even minor damage can cause considerable reduction in structural integrity. To ensure that a damaged structure will not catastrophically fail during service life and will maintain maxi mum structural efficiency, it is necessary to carry out damage tol erance studies, evaluating the residual properties of the structure after impact [3].

In the review on composite damage tolerance by Abrate [4], most of the studies referenced deal with compression after impact behaviour, while fewer studies analyse tensile after impact behav iour and very few treat residual flexural properties. Since the pub

* Corresponding author. Tel.: +34 9162488 82; fax: +34 916249430. E-mail address: ssanchez@ing.uc3m.es (S. Sanchez-Saez). lication of that book, the trend has not changed, and residual compressive properties are evaluated in more works [5 10] than are residual flexural properties [11 13]. The lower number of flex ural residual properties studies may be because the flexural loads introduce a complex stress pattern and, therefore, the effect on residual properties of the test parameter is harder to analyse [14].

The aim of a damage tolerance study is to evaluate the capacity of a structural element to continue carrying out its functions after an impact; for this reason, in a beam designed to bear bending mo ments, it is necessary to evaluate the residual flexural properties.

Most researchers studying flexural damage tolerance generate the damage by an out of plane impact on plate specimens with a impactor having a hemispherical nose, and afterwards they cut the specimen into beam specimens to evaluate the flexural resid ual properties $[11,15,16]$. The drawback of this technique is that the damage to a plate could differ from that inflicted on a beam. Also, the cutting process could produce additional damage in the specimen. To avoid this additional damage, Zhang and Richardson [12] used specimens with a geometry halfway between a beam and a plate, $140 \times 40 \mathrm{~mm}^{2}$. To generate the damage, the specimens were pneumatically clamped between to $65 \mathrm{~mm}$ circular ring and anvil and were impacted with a hemispherical nose impactor. The residual properties were evaluated from beams tested under a three point bending configuration.

Few studies concern the flexural residual behaviour of beams damaged by bending [13,17]. Rotem [17] studied the influence of the material, testing a carbon/epoxy laminate and a less brittle glass/epoxy laminate. Three point bending tests were conducted 
in a drop weight tower to damage the beam. Afterwards, the resid ual properties were evaluated by static three point bending tests. Chenghong et al. [13] studied the influence of three different fibres (aramid, glass, and basalt) in the impact damage modes and resid ual flexural properties of unidirectional laminates. They observed that the reduction in residual flexural modulus was slightly greater than the reduction in strength.

There is a lack of knowledge concerning the residual strength of composite beams. The influence of some parameters, such as mechanical properties of the composite, has been analysed previ ously $[13,17]$. However, there are other parameters such as speci men geometry and impactor nose for which the influence on bending residual properties has not been thoroughly studied.

The present work analyses the influence of impact energy, spec imen width, and impactor nose geometry on the flexural residual strength of a composite beam by experimental tests. Damage was induced in the middle section of simply supported beams by bending impact tests. The reduction of the flexural residual strength was evaluated by quasi static three point bending tests.

\section{Experimental}

\subsection{Material}

This study used a laminate $3 \mathrm{~mm}$ thick made up of five plain woven plies of glass E fibre (RT 270 1546) and polyester resin ARO POL FS6902. This laminate is frequently used in diverse industries, such as the automotive and naval industries, because it has a very good relation between mechanical properties and cost.

\subsection{Impact tests}

Low velocity impact tests were performed using a three point bending configuration to damage specimens. Specimens with two different widths ( $20 \mathrm{~mm}$ and $50 \mathrm{~mm}$ ) were tested. For each speci men type, two impactor noses were used, one being a Charpy nose, and the other a hemispherical nose. The impactor nose used for each specimen width was designed to maintain the same geomet ric ratios with the corresponding specimens. A total of four test configurations were carried out, Table 1.

The support span $(90 \mathrm{~mm})$ was selected so as to disregard trans verse shear forces, both in the displacements and in the failure of the beam, according to the results of a previous study on the influ ence of transverse shear forces in the three point bending tests of composite beams $[18,19]$.

In the impact tests a drop weight tower, CEAST Fractovist 6785 , instrumented to register the load exerted by the impactor, was used. Different impact energies were selected for each test config uration (Table 1).
Each test provided a record of the load applied to the specimen by the impactor. The displacement history of the impactor could be cal culated by integrating the load history with the use of impact velocity

$x(t) \quad \int_{0}^{t}\left[v_{0} \quad \int_{0}^{t} \frac{F(t) \quad m \cdot g}{m} d t\right] d t$

where $v_{0}$ is the impact velocity, $F(t)$ the load history, $m$ the impactor mass, and $g$ is the acceleration of gravity.

The impact velocity can be estimated by the height from which the impactor is dropped; nevertheless, when the impactor reaches the specimen, the velocity is lower than the predicted one due to the friction undergone during the fall. For an accurate calculation of the impact velocity, tests were recorded by a high speed video camera Photron APX RS, which allows up to 250,000 images to be taken per second. This technique enabled an evaluation of the failure mode of the specimens.

Based on load and displacement histories, the history of energy transferred from the impactor to the beam could be calculated (Eq. (2)). The absorbed energy was termed as the amount of energy trans ferred from the impactor to the beam at the end of an impact event.

$E(t) \quad \int_{0}^{t} F(t)\left[v_{0} \quad \int_{0}^{t} \frac{F(t) \quad m \cdot g}{m} d t\right] d t$

\subsection{Bending after impact tests}

The post impact strength of impacted specimens was evaluated by three point bending tests under static conditions. The tests were conducted according to the standard ASTM D 79098 , since there is no standard to evaluate residual flexural properties. The three point bending load was applied at a constant cross head rate of $4.5 \mathrm{~mm} /$ min (strain rate of $0.01 \mathrm{~min}^{1}$ ) on the specimen impacted side, so that the impacted side underwent a compression stress.

The tests were performed using a universal testing machine, In stron 8516 , with a load cell of $5 \mathrm{kN}$. A three point bending device was used to test damaged beams, using the same support span as in the impact tests, $90 \mathrm{~mm}$. In order to evaluate the residual flex ural strength of the impacted specimens, it was first necessary to know the properties of non damaged specimens. Five static three point bending tests (reference tests) were made for the geometry of each specimen.

\section{Results}

\subsection{Impact tests}

Damage mechanisms developed in a similar way in the four test configurations: fibre breakage and matrix cracking were detected

Table 1

Impact-test configurations.

\begin{tabular}{|c|c|c|c|c|c|}
\hline & & T20C & $\mathrm{T} 20 \mathrm{H}$ & $\mathrm{T} 50 \mathrm{C}$ & $\mathrm{T} 50 \mathrm{H}$ \\
\hline \multirow{3}{*}{ Specimen geometry } & Width & $20 \mathrm{~mm}$ & $20 \mathrm{~mm}$ & $50 \mathrm{~mm}$ & $50 \mathrm{~mm}$ \\
\hline & Length & $120 \mathrm{~mm}$ & $120 \mathrm{~mm}$ & $120 \mathrm{~mm}$ & $120 \mathrm{~mm}$ \\
\hline & Thickness & $3 \mathrm{~mm}$ & $3 \mathrm{~mm}$ & $3 \mathrm{~mm}$ & $3 \mathrm{~mm}$ \\
\hline \multicolumn{2}{|l|}{ Support span } & $90 \mathrm{~mm}$ & $90 \mathrm{~mm}$ & $90 \mathrm{~mm}$ & $90 \mathrm{~mm}$ \\
\hline \multirow{3}{*}{ Impactor-nose } & Nose & Charpy & Hemispherical & Charpy & Hemispherical \\
\hline & Geometry & Width: $20 \mathrm{~mm}$ & Diameter: 8 mm & Width: $50 \mathrm{~mm}$ & Diameter: $20 \mathrm{~mm}$ \\
\hline & & Radius: 5 mm & & Radius: $10 \mathrm{~mm}$ & \\
\hline \multirow[t]{5}{*}{ Impact energies } & & $8 \mathrm{~J}$ & $8 \mathrm{~J}$ & $10 \mathrm{~J}$ & $10 \mathrm{~J}$ \\
\hline & & $11 \mathrm{~J}$ & $11 \mathrm{~J}$ & $15 \mathrm{~J}$ & $15 \mathrm{~J}$ \\
\hline & & $14 \mathrm{~J}$ & $14 \mathrm{~J}$ & $20 \mathrm{~J}$ & $20 \mathrm{~J}$ \\
\hline & & & & $25 \mathrm{~J}$ & $25 \mathrm{~J}$ \\
\hline & & & & $30 \mathrm{~J}$ & $30 \mathrm{~J}$ \\
\hline
\end{tabular}




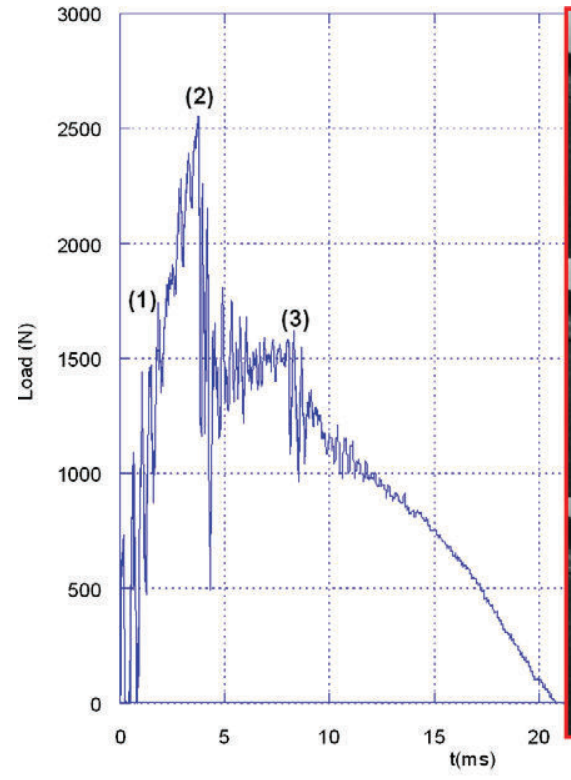

(a)

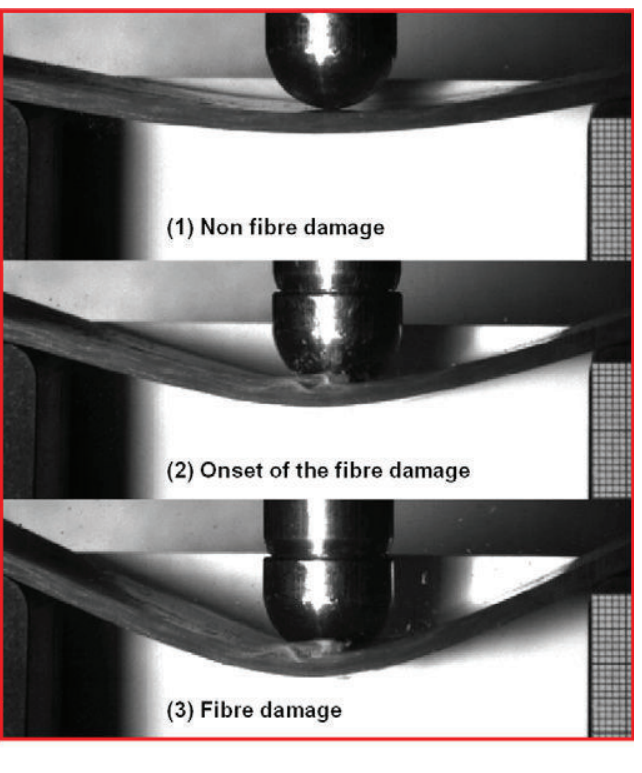

(b)

Fig. 1. Load history.

in the contact area of the specimen with the impactor, and no delamination was detected. The lack of damage by delamination may be due to the greater interlaminar and intralaminar strength conferred by the structure of the reinforcement in plain woven laminates [20]. In the tests at the lowest impact energies used, the damage took place only in the central surface of the contact area. As the impact energy increased, the damage spread until reaching the edges of the beam.

A representative load history of all the tests is shown in Fig. 1. Images of the specimen at different times during the test, recorded by a high speed video camera, was added to this figure. For loads lower than the maximum load, such as point 1 in the load time curve, no failure in the specimen was observed. At point 2 in the load history, an explosive failure of fibres was vis ible in the image in the contact area between specimen and impactor. This load was defined in this work as peak load, and represents the onset of the fibre damage. Successive explosive failures noted in the recorded images correspond to points in the load time curve where there were sudden oscillations of load, as in point 3.

Because the tested specimens had different widths, in order to compare the experimental results from the different configura tions, two parameters were defined: the impact energy factor, as the impact energy divided by the cross section area of the speci men and the absorbed energy factor, as the absorbed energy di vided by the cross section area.

Fig. 2 shows the peak load versus the impact energy factor. Two families of curves result, corresponding to the two specimen width, and the peak load is higher in the wider specimens due to the greater stiffness. The influence of the impactor nose is not signifi cant at peak load, according to the results. Many authors consider the peak load to increase linearly with the impact energy [21,22]; however, despite the great dispersion found in the results, this behaviour was not found.

When the impact energy increased, the peak load did not appre ciably vary. On the contrary, the absorbed energy increased signif icantly (Fig. 3), and therefore it can be considered an indicative parameter of specimen damage.

Several damage mechanisms affect the absorbed energy, and thus a small difference in any test variable can prompt a great dif

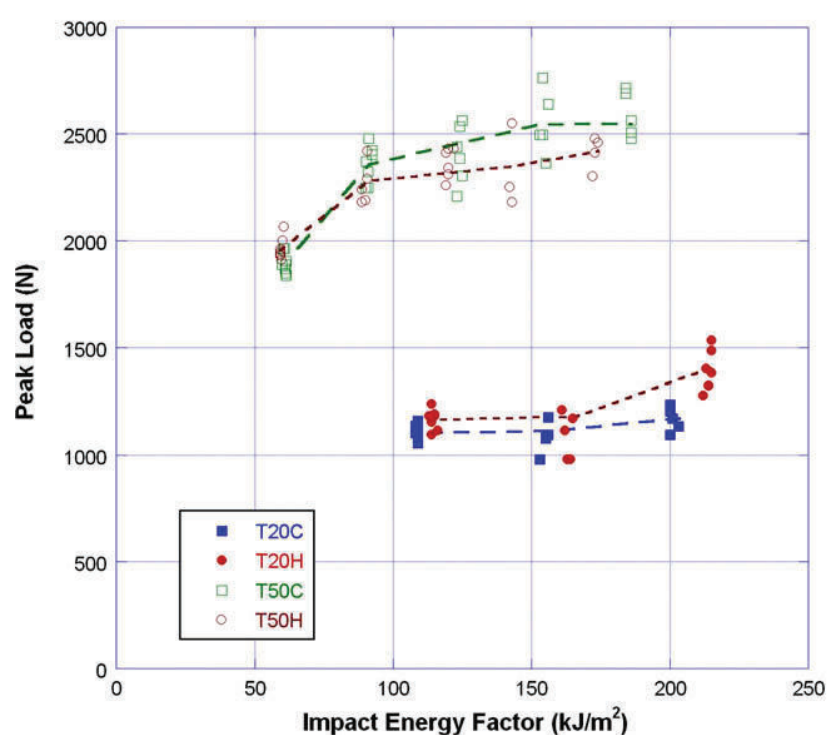

Fig. 2. Peak load variation with impact-energy factor.

ference in the test results. For this reason, scatter in the results was notable (Fig. 3), as is quite usual in glass laminate tests [12,16,17].

When the impact energy is very low, there was no energy absorption during the impact. There was a level of impact energy factor that caused fibre and matrix failure in the central surface of the contact area and, consequently, the specimen started to ab sorb energy. This impact energy factor which started the damage was lower in the wider specimens because the contact load was greater. From this value of the impact energy factor, damage in creased in the middle span and the absorbed energy factor in creased in an approximately lineal way with the impact energy factor. When damage reached the edges of the specimen the ab sorbed energy factor changed trend because the capacity of the beam to absorb energy was restricted. This change in trend was ob served for lower impact energy factors in the specimens tested with the Charpy nose impactor, since the impact took place over 

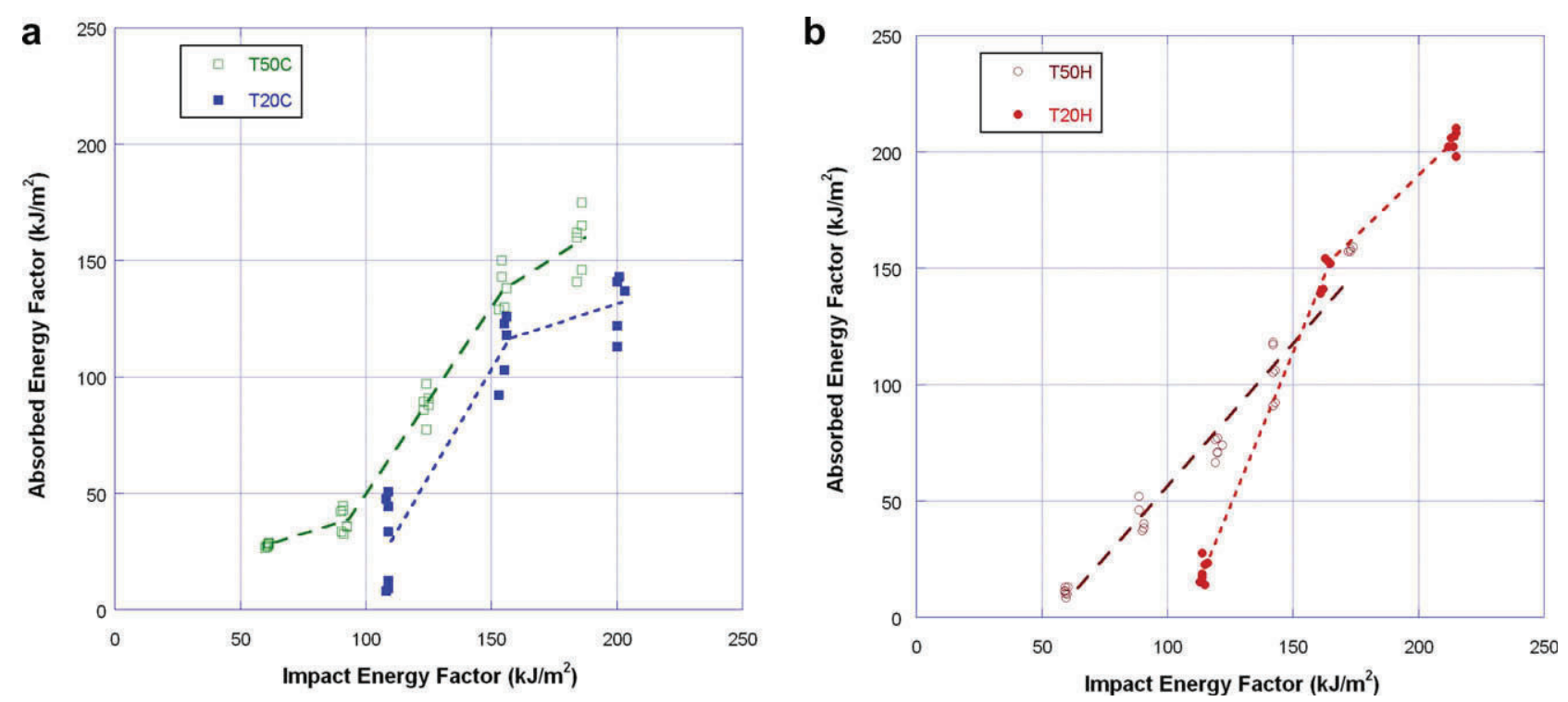

Fig. 3. Variation of absorbed-energy factor with impact-energy factor.

Table 2

Reference flexural strength.

\begin{tabular}{lll}
\hline Specimen width $(\mathrm{mm})$ & Main value $(\mathrm{MPa})$ & Coefficient of variance $(\%)$ \\
\hline 20 & 746 & 5 \\
50 & 684 & 5 \\
\hline
\end{tabular}

the entire width of the specimen beam. The damage reached the edges of the beam for lower energy factors in narrow specimens so that the T20C is the test configuration in which the change of trend in the absorbed energy factor was associated with a lower impact energy factor. For the same reason, in T50H tests this change of trend was not detected because the damage did not reach the whole width of the beam in the selected energy range.

\subsection{Bending after impact tests}

The results of the reference three point bending tests con ducted on non damaged specimens are shown in Table 2.

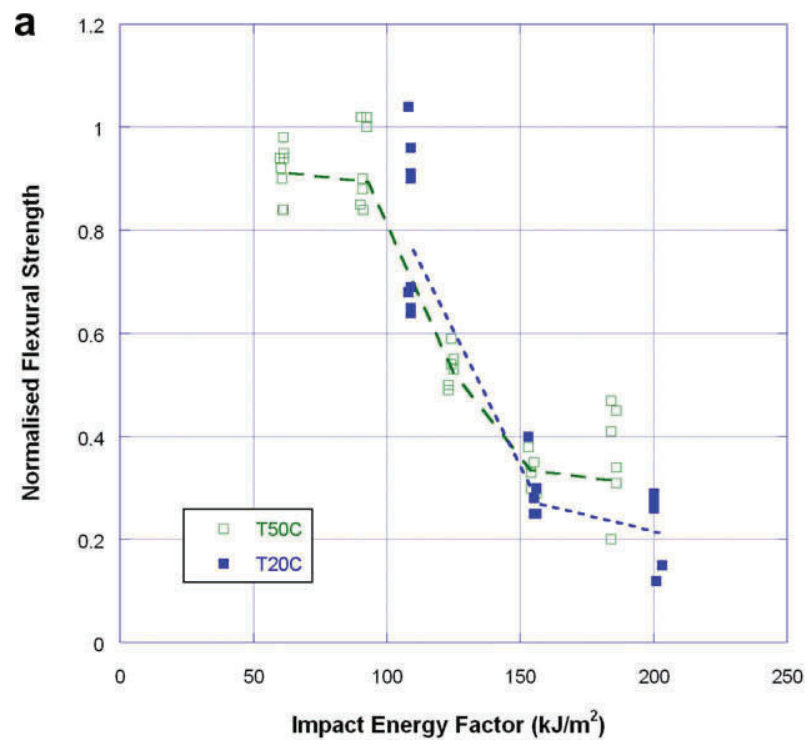

In an examination of the reference tests results, it is notewor thy that the strength in the narrow specimens was slightly higher (8\%) than in the wide ones. This difference was not significant be cause it was close to the coefficient of variation. Furthermore, this phenomenon is usual in laminate composites due to their sensitiv ity to internal defects, so that the wider the maximum stress area, the higher possibility to find defects. In fact, the flexural strength in composite materials is higher than tensile strength because, in the bending test, only the outer plies receive maximum stress while in tensile test the whole section is subjected to the maximum stress. Wisnom [23] explained this phenomenon in terms of the Weibull statistics, considering that critical defects are statistically distrib uted in the material.

For a better indication of the influence of the impact damage on the residual properties, the normalised flexural strength of each specimen was calculated as the strength of the impacted specimen divided by the mean value of the strength of the reference test. Fig. 4 shows the variation of this parameter with the impact en ergy factor.

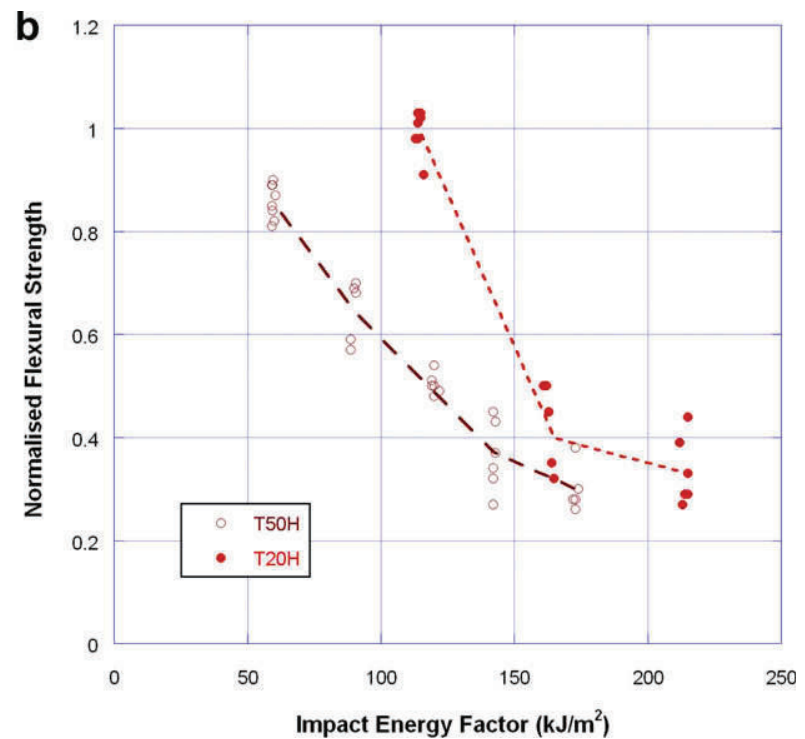

Fig. 4. Residual normalised flexural-strength variation with impact-energy factor. 


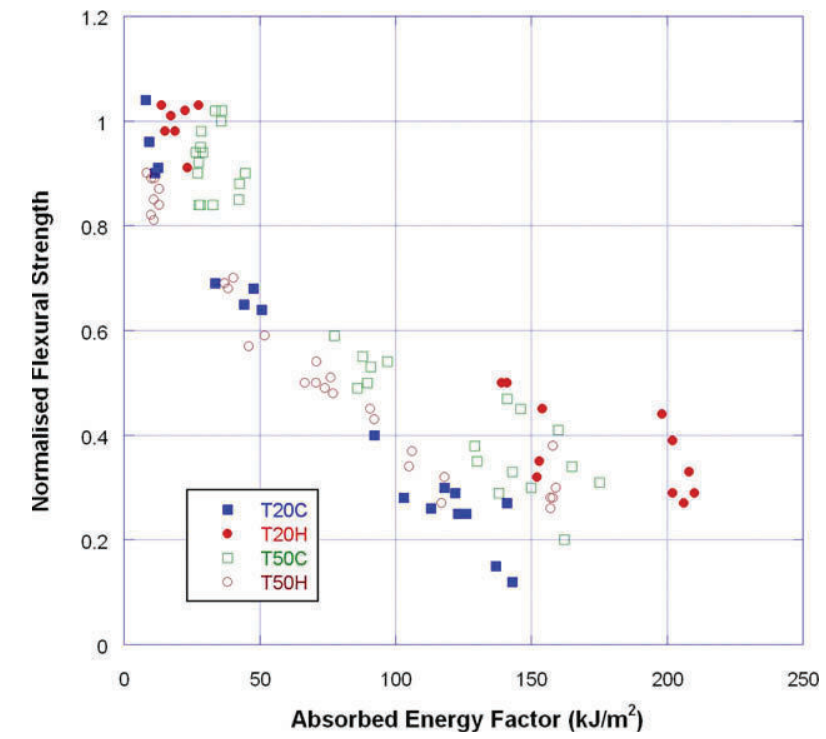

Fig. 5. Variation of residual normalised flexural strength with absorbed energy.

Figs. 3 and 4 reveal a relationship between residual flexural strength, absorbed energy, and impact energy. The lower impact energy factor in which the specimens absorb energy produces damage that diminishes the residual strength. The lineal relation ship observed between the impact energy factor and the ab sorbed energy factor is reflected in a lineal relationship between the fall of the residual strength and the impact energy factor until the residual strength has suffered a loss of $6070 \%$. When damage reached the edges of the beam, specimen capacity to absorb energy was restricted so that a change of tendency both in the absorbed energy factor and residual strength was found. This behaviour has also been observed by other authors analysing residual flexural properties [12]. The biggest loss of residual strength takes place in the T20C specimens in which the damage reaches the edges of the specimen for a lower absorbed energy factor.

When the loss of residual strength was plotted against the ab sorbed energy factor the same trend appeared for all the test con figurations (Fig. 5). When the beam absorbed a minimum of energy, the residual strength was close to the reference strength because damage was located in the contact area. As the absorbed energy increased, the residual strength declined in an approxi mately lineal way. When the damage reached the edges of the beam, both the absorbed energy and residual strength showed a change of trend. Two regions with a high scatter were observed, Fig. 5. These regions correspond to the absorbed energy factors in which a change in the trend was noticed: firstly, for values of the absorbed energy factor close to zero associated with the onset of damage, and secondly for values of the absorbed energy factor close to $150 \mathrm{~kJ} / \mathrm{m}^{2}$ associated with damage over the whole width of the beam and, therefore, to the change of trend in residual strength.

Significant differences of impactor nose and specimen size were observed in the damage associated with an absorbed energy factor. However, specimens with a similar absorbed energy factors show a similar residual flexural strength regardless of the impac tor nose or of specimen size.

\section{Conclusions}

This study analyses the influence of impact energy, beam width, and impactor nose on the residual flexural strength of a composite beam. The main conclusions are:
- From a certain impact energy factor, fibre failure and matrix cracking start in the contact area. The beam width was found to influence the impact energy factor needed to initiate the damage, this being lower in wider specimens.

- From this value, when the impact energy increases, damage is greater and absorbed energy factor augments almost linearly. Since absorbed energy increases, the residual flexural strength decreases almost linearly with the impact energy factor.

- When specimen damage reaches the edges of the beam the capacity of the beam to absorb energy is restricted, changing the trend of the absorbed energy factor, and therefore the trend of the residual flexural strength also changes.

- The beam width and the impactor nose were found to influence damage evolution. In Charpy nose tests, damage reaches the edges of the beam for a lower impact energy factor than in hemispherical nose tests. In narrow specimens, damage reaches the edges of the beam for a lower impact energy factor.

- The greatest loss in residual strength occurs in T20C specimens because damage reaches the edges of the beam for a lower impact energy factor.

- Despite the influence of the impactor nose and beam width on the absorbed energy and the residual flexural strength, neither the impactor nose nor beam width have a significant influence on the relationship between absorbed energy and residual strength.

\section{References}

[1] Mangalgiri PD. Composite materials for aerospace applications. Bull Mater Sci 1999;22(3):657-64.

[2] Demakos CB. Stress fields in fiber reinforced laminate beams due to bending and torsion moments. J Reinf Plast Compos 2003;22(5):399-418.

[3] MIL-HDBK-17-3E. Polymer matrix composites. Materials usage, design and analysis. Department of defense handbook, vol. 3. Department of Defense of United States of America; 1997.

[4] Abrate S. Impact on composite structures. Cambridge University Press; 1998.

[5] Khondker OA, Herszberg I, Hamada H. Measurements and prediction of the compression-after-impact strength of glass knitted textile composites. Compos Part A: Appl Sci Manufact 2004;35(2):145-57.

[6] Sánchez-Sáez S, Barbero E, Zaera R, Navarro C. Compression after impact of thin composite laminates. Compos Sci Technol 2005;65(13): 1911-9.

[7] Zhang X, Hounslow L, Grassi M. Improvement of low-velocity impact and compression-after-impact performance by z-fibre pinning. Compos Sci Technol 2006;66(15):2785-94.

[8] Schubel PM, Luo J-J, Daniel IM. Impact and post impact behaviour of composite sandwich panels. Compos Part A: Appl Sci Manufact 2007;38: 1051-7.

[9] Sanchez-Saez S, Barbero E, Navarro C. Compressive residual strength at low temperatures of composite laminates subjected to low-velocity impacts. Compos Struct 2008;85(3):226-32.

[10] Sihn S, Kim RY, Kawabe K, Tsai SW. Experimental studies of thin-ply laminated composites. Compos Sci Technol 2007;67:996-1008.

[11] Amaro AM, Reis PNB, Moura MFSF. Residual strength after low velocity impact in carbon-epoxy laminates. Mater Sci Forum 2006;514-516:624-8.

[12] Zhang ZY, Richardson MOW. Low velocity impact induced damage evaluation and its effect on the residual flexural properties of pultruded GRP composites. Compos Struct 2007;81:195-201.

[13] Chenghong H, Yubin L, Zuoguang Z, Zhijie S. Impact damage modes and residual flexural properties of composite beam. J Reinf Plast Compos 2008;27(11):1163-75.

[14] Richardson MOW, Wisheart MJ. Review of low-velocity impact properties of composites materials. Compos Part A: Appl Sci Manufact 1996;27:1123-31.

[15] Kim J-K, Mackay DB, Mai Y-W. Drop-weight impact damage tolerance of CFRP with rubber-modified epoxy matrix. Composites 1993;24(6):485-94.

[16] Mouritz AP. The effect of underwater explosion shock loading on the flexural properties of GRP laminates. Int J Impact Eng 1996;18:129-39.

[17] Rotem A. Residual flexural strength of FRP composite specimens subjected to transverse impact loading. SAMPE J 1988;24:19-25.

[18] Santiuste C, Sanchez-Saez S, Barbero E. Application of the flexibility influence functions method in the dynamic analysis of composite beams. J Solids Struct 2007;44:4795-809.

[19] Santiuste C. Análisis y modelización de vigas de tipo laminado sometidas a cargas impulsivas. Ph.D. Thesis. Carlos III University of Madrid; 2007 [in Spanish]. 
[20] Sanchez-Saez S, Barbero E, Navarro C. Analysis of the dynamic flexura behaviour of composite beams at low temperature. Compos Sci Technol 2007;67:2616-32.

[21] Cantwell WJ, Morton J. The impact resistance of composite materials - a review. Composites 1991;22:347-62.
[22] Schoeppner GA, Abrate S. Delamination threshold loads for low velocity impact on composite laminates. Compos Part A: Appl Sci Manufact 2000;31(9):903-15

[23] Wisnom MR. The relationship between tensile and flexural strength of unidirectional composites. J Compos Mater 1992;30:357-67. 